\title{
My Quibble with the term "Functional Foods" Rogers Harry-O'kuru*
}

US Department of Agriculture, Agricultural Research Service, National Center for Agricultural Utilization Research, USA

For long, I have been wondering what the above appellation really infers. And I am yet to encounter an expert who, in simple terms, would educate me on what Functional Foods are. Does the coiners of this new name mean that the traditional unprocessed food stuff like wild rice, wheat, plantain, bananas, potatoes, yams, etc. which have healthfully sustained countless generations of older persons in the absence of synthetic additives and preservatives were not functional as food?

I am aware that commercial food manufacturers and processors may have bought wholeheartedly into this sexy name in these fast moving times in which "New" may be construed as better but it seems that its claim to acceptance is only skin deep, a marketing ploy at best to mislead the busy unwary public into polluting their internal environment with tasty food that does the body no good as an energy source for healthy living. It is true the physical body was never intended to live forever, but a little more care in what is fed to it makes a lot of difference. In other words, buyer of functional foods, be careful!

Pay more attention to home cooked, least processed, natural food stuff that have all the inherent nutrients which the body needs. Now, the day may come when all the dinosaurs are converted to the choir of the genomists but then also we would all have a glut of information regarding these matters freely available to the public so that each of us can decide for ourselves what the odds are rather than simply buying a pig in a poke, as the old saying goes.
*Corresponding author: Rogers Harry-O'kuru, US Department of Agriculture, Agricultural Research Service, National Center for Agricultural Utilization Research, USA, Tel: +1-309-681-6341; Fax: +1-309-681-6689; E-mail: rogers.harryokuru@ars.usda.gov

Received July 23, 2012; Accepted July 24, 2012; Published July 25, 2012

Citation: Harry-O'kuru R (2012) My Quibble with the term "Functional Foods". J Food Process Technol 3:e106. doi:10.4172/2157-7110.1000e106

Copyright: @ 2012 Harry-O'kuru R. This is an open-access article distributed under the terms of the Creative Commons Attribution License, which permits unrestricted use, distribution, and reproduction in any medium, provided the original author and source are credited. 